\title{
AN INVERSE PROBLEM FOR HELMHOLTZ'S EQUATION
}

\author{
A.G. RAMM \\ Mathematics Department \\ Kansas State University \\ Manhattan, KS 66506 \\ (Received March 20, 1987)
}

ABSTRACT. The refraction coefficient in Helmholtz's equation is found from the knowledge of a family of the solutions to this equation on two lines.

KEYS WORDS AND PHRASES. Helmholtz equation, inverse problem, Born approximation. 1980 AMS SUBJECT CLASSIFICATION CODE. 35R30, 35J05.

1. INTRODUCTION.

Let

$$
\left[\nabla^{2}+k^{2}+k^{2} v(x)\right] u=-\delta(x-y), k>0
$$

where $x=\left(x_{1}, x_{3}\right), y=\left(y_{1}, y_{3}\right), v=v\left(x_{1}, x_{3}\right), u=u\left(x_{1}, x_{3}, y_{1}, y_{3}, k\right)$.

Assume that

$$
v(x)=0 \text { for } x_{1} \geqq a \text { or } x_{1} \leqq-a \text {, or } x_{3} \geqq 0 \text { or } x_{3} \leqq-R, v \varepsilon L^{2}
$$

Here $R>0$ is an arbitrary large fixed number. Write (1.1) as

$$
u=g+k^{2} \int \operatorname{gvudz}, g:=(i / 4) H_{0}^{(1)}(k|x-y|)
$$

where the integral is taken over the support of $\mathrm{v}$ and $\mathrm{H}_{0}^{(1)}$ is the Hankel function.

The problem is: find $\mathrm{v}(\mathrm{k})$ from the knowledge of $\mathrm{u}\left(-\mathrm{a}, \mathrm{x}_{3}, \mathrm{a}, \mathrm{y}_{3}, \mathrm{k}\right)$ for all $-\infty<\mathrm{x}_{3}, \mathrm{y}_{3}<\infty$ and $0<\mathrm{k}<\mathrm{k}_{0}$, where $\mathrm{k}_{0}>0$ is an arbitrary small number.

2. SOLUTION.

Let $L_{a}=\left\{x: x_{1}=a, x_{3} \varepsilon R^{1}\right\}, R^{1}=(-\infty, \infty)$. We use the method given in [1], [2]. It follows from (1.3) that

$$
f\left(x_{3}, y_{3}, k\right):=k^{-2}(u-g)=\int g v g d z+o(k) \text { as } k \rightarrow 0, x \varepsilon L_{-a}, y \in L_{a} \text {. }
$$

Let us take the Fourier transform of (2.1) in $x_{3}$ and $y_{3}$, define $\tilde{f}(\lambda, \mu):=(2 \pi)^{-2} \int_{-\infty}^{\infty} \exp \left(-i \lambda x_{3}-1 \mu y_{3}\right) f\left(x_{3}, y_{3}\right) d x_{3} d y_{3}$, and use the formula

$$
(2 \pi)^{-1} \int_{-\infty}^{\infty} \exp \left(-1 \lambda x_{3}\right) g(x, z) d x_{3}=1(4 \pi)^{-1} \exp \left\{-1 \lambda z_{3}+1\left(a+z_{1}\right)\left(k^{2}-\lambda^{2}\right)^{\frac{1}{2}}\right\} /\left(k^{2}-\lambda^{2}\right)^{\frac{1}{2}}
$$


where $\mathrm{x}=\left(-\mathrm{a}, \mathrm{x}_{3}\right)$, the radical $\left(\mathrm{k}^{2}+\mathrm{io}-\lambda^{2}\right)^{\frac{1}{2}}>0$ for $\lambda^{2}<\mathrm{k}^{2}$ and is defined by analytic continuation for all complex $\lambda$ on the complex $\lambda-$ plane with the cut $(-k, k), k>0$, so that

$$
\left(k^{2}-\lambda^{2}\right)^{\frac{1}{2}}=i\left(\lambda^{2}-k^{2}\right)^{\frac{1}{2}} \text { if } \quad k^{2}<\lambda^{2}
$$

The result is

$$
\tilde{\mathrm{f}}(\lambda, \mu)=\int \mathrm{d} z \mathrm{v}(z) \mathrm{h}(\lambda, \mu, z, \mathrm{k})+o(\mathrm{k})
$$

where for $k^{2}>\lambda^{2}, k^{2}>\mu^{2}$, and $r(\lambda):=\left(k^{2}-\lambda^{2}\right)^{\frac{1}{2}}$ one has

$$
h:=-\left(16 \pi^{2}\right)^{-1} \exp \left\{-i(\lambda+\mu) z_{3}+i\left(a+z_{1}\right) r(\lambda)+1\left(a-z_{1}\right) r(\mu)\right\} r^{-1}(\lambda) r^{-1}(\mu)
$$

and for $\mathrm{k}^{2}<\mu^{2}$ and $\mathrm{k}^{2}<\lambda^{2}$ one uses (2.3).

In the Born approximation one drops the term $o(k)$ in $(2.4)$ and solves the resulting linear integral equation for $v(z)$ [2].

In the exact theory one passed to the limit $k \rightarrow 0$ in (2.4), obtains a linear integral equation for $\mathrm{v}$ and solves this equation analytically [2]. It is not possible to pass to the limit $k \rightarrow 0$ in $(2.1)$ because $g(k r)=\alpha(k)+g_{0}+0\left[(k r)^{2} \ln (k / 2)\right]$ as $k \rightarrow 0$, where $g_{0}:=(2 \pi)^{-1} \ln \left(r^{-1}\right), \alpha(k):=-(2 \pi)^{-1} \ln (k / 2)+i / 4-\gamma /(2 \pi)$, and $\gamma=0.5572 \ldots$ is Euler's constant. Thus $\mathrm{g}(\mathrm{kr})$ does not have a finite limit as $k+0$. Nevertheless one can pass to the limit $k \rightarrow 0$ in (2.4) if $\gamma \neq 0$ or $\mu \neq 0$. The reason is that the term $\alpha(k)$ in (2.1) after the Fourier transform becomes $\alpha(k) \delta(\lambda) \delta(\mu)$, and this term, which contains the factor $\alpha(k) \rightarrow \infty$ as $k \rightarrow 0$, is zero for $\lambda \neq 0$ or $\mu \neq 0$. Another way to study the 11mit behavior of the solution to (2.1) is given in [2]. To give the exact theory, pass to the limit $k \rightarrow 0$ in (2.4) to get

$$
\int \mathrm{v}(\mathrm{z}) \exp \left(-1 \mathrm{pz_{3 }}+\mathrm{qz} \mathrm{z}_{1}\right) \mathrm{d} \mathrm{z}_{1} \mathrm{~d} \mathrm{z}_{3}=\psi(\mathrm{p}, \mathrm{q})
$$

where we used (2.5) and set

$$
\begin{aligned}
& \mathrm{p}:=\lambda+\mu, \mathrm{q}:=|\mu|-|\lambda|, \\
& \psi(\mathrm{p}, \mathrm{q}):=16 \pi^{2} \tilde{\mathrm{f}}(\lambda, \mu)|\lambda||\mu|\{\exp \mathrm{a}(|\lambda|+|\mu|)\}
\end{aligned}
$$

and the right side of (2.8) should be expressed as a function of $(p, q)$ by formulas $(2.7)$.

If $\mu>0$ and $\lambda>0$ then the point $(p, q)$ defined by $(2.7)$ runs through $\mathrm{Q}_{+}=\{\mathrm{p}, \mathrm{q}:|\mathrm{q}|<\mathrm{p}, \mathrm{p}>0\}$.

If $\lambda<0$ and $\mu<0$ then $(p, q)$ runs through $Q_{-}=\{p, q:|q|<-p, p<0\}$. If $\psi(p, q)$ is known in $Q_{+} c r Q_{-}$then $v(z)$ can be uniquely recovered from (2.6) by the analytical methods given in [2] p. 270-274, where inversion of the Fourier and Laplace transforms of compactly supported functions from a compact set is given. This inversion problem is ill-posed and its numerical implementation is not a simple matter.

One can use the same ideas to solve equation (2.4) at a fixed $k>0$ in the Born approximation. The basic equation analogous to (2.4) for the case when $-k<\lambda$, $\mu<k$, is : 


$$
\int \mathrm{v}(\mathrm{z}) \exp \left\{-i\left(\mathrm{pz}_{3}+\mathrm{q}_{1} \mathrm{z}_{1}\right)\right\} \mathrm{dz}=\mathrm{f}\left(\mathrm{p}, \mathrm{q}_{1}\right) \text { for }-\mathrm{k}<\mu, \lambda<\mathrm{k}
$$

where $\mathrm{p}=\lambda+\mu, \mathrm{q}_{1}:=\mathrm{r}(\mu)-\mathrm{r}(\lambda)$,

$$
F\left(p, q_{1}\right):=-16 \pi^{2} \tilde{f}(\lambda, \mu) r(\lambda) r(\mu) \exp \{-i a[r(\lambda)+r(\mu)]\}
$$

and the right side of (2.10) should be expressed as a function of $p, q_{1}$.

If $(\lambda, \mu) \quad\{\lambda, \mu:|\lambda|>k$ and $|\mu|>k, \lambda, \mu$ are real $\}$ then the basic equation in the Born approximation is equation (2.6) in which the right side is now given by the formula $\psi=F$, where $F$ is defined by (2.10) and in (2.10) the radicals $r(\lambda)$ and $r(\mu)$ are computed by formula (2.3) for $\lambda^{2}>\mathrm{k}^{2}$ and $\mu^{2}>\mathrm{k}^{2}$.

Equation (2.9) can also be solved analytically with the prescribed accuracy by the methods given in [2].

The problem considered is of interest in application.

\section{REFERENCES}

1. RAMM, A.G. Inverse Scattering for Geophysical Problems, Phys. Letters 99A (1983), 258-260.

2. RAMM, A.G. Scattering by Obstacles, (Dordrecht: Reide1). 


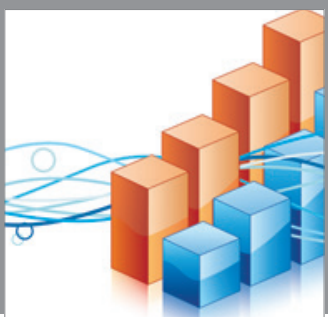

Advances in

Operations Research

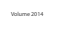

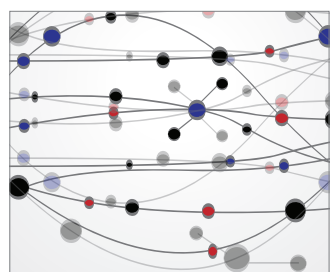

\section{The Scientific} World Journal
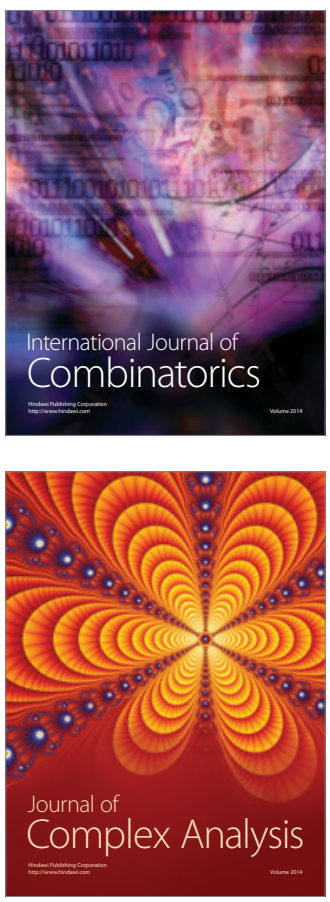

International Journal of

Mathematics and

Mathematical

Sciences
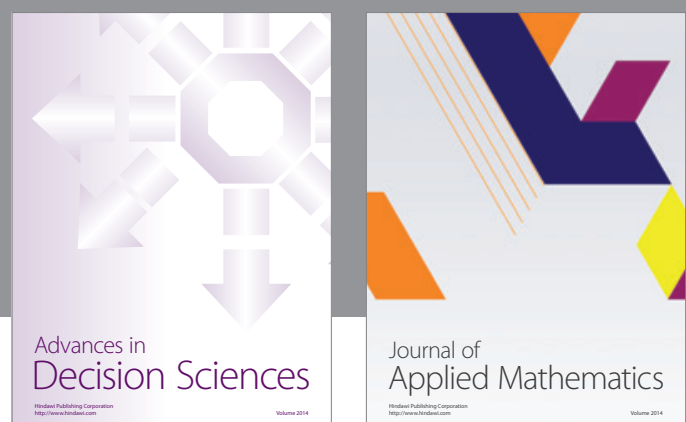

Journal of

Applied Mathematics
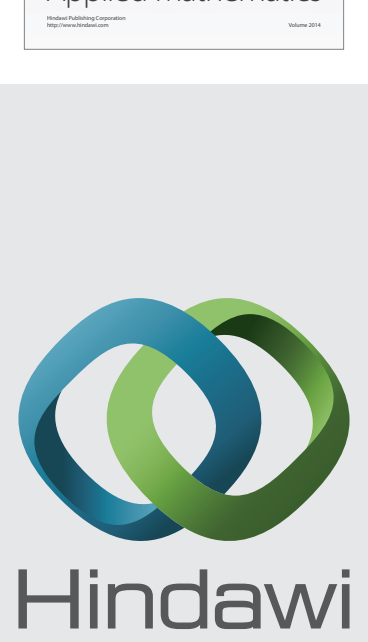

Submit your manuscripts at http://www.hindawi.com
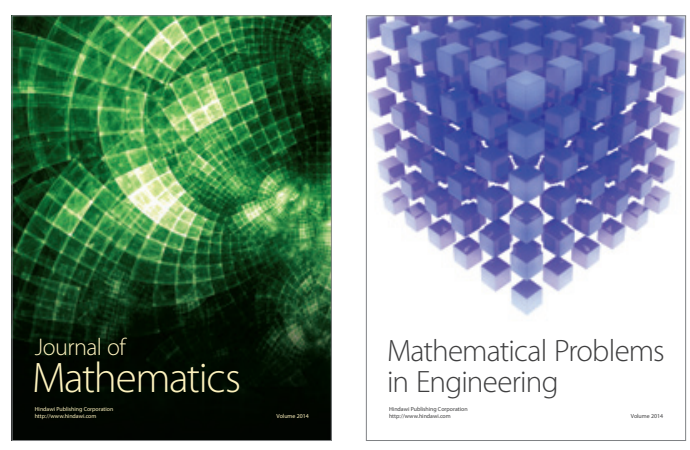

Mathematical Problems in Engineering
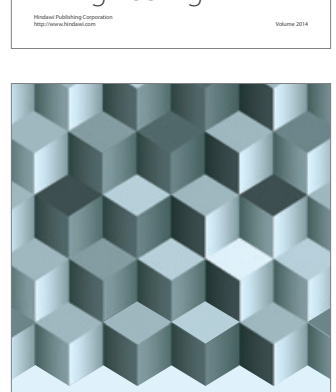

Journal of

Function Spaces
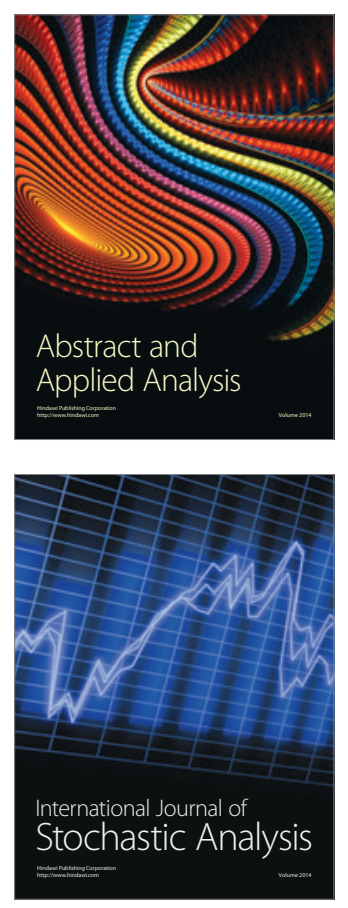

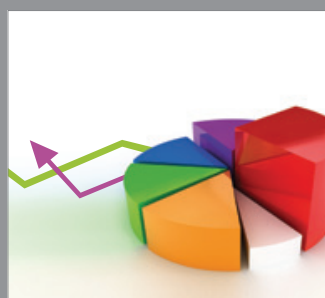

ournal of

Probability and Statistics

Promensencen
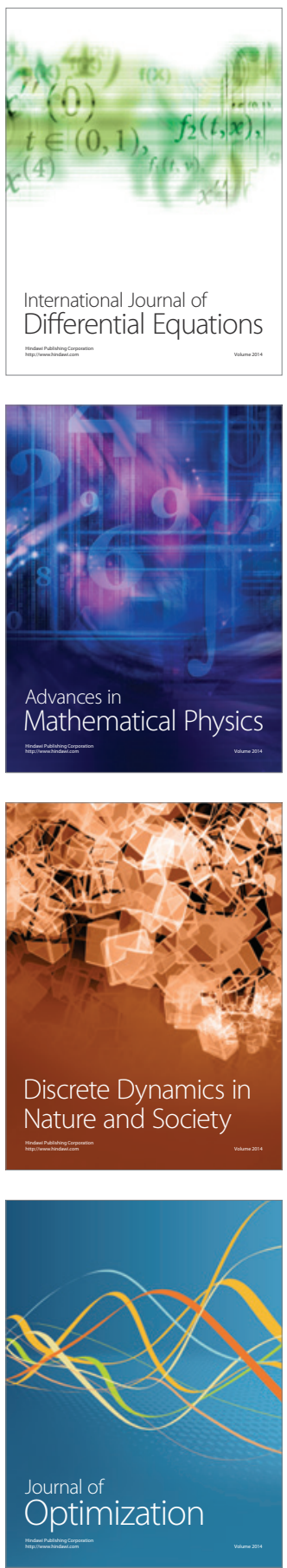